Published in final edited form as:

Curr Epidemiol Rep. 2019 June ; 6(2): 104-111. doi:10.1007/s40471-019-00188-3.

\title{
The changing epidemiology of primary liver cancer
}

\author{
Jessica L. Petrick ${ }^{1}$ and Katherine A. McGlynn ${ }^{1}$ \\ ${ }^{1}$ Division of Cancer Epidemiology and Genetics, National Cancer Institute, Bethesda, MD
}

\section{Abstract}

Purpose of Review: In prior decades, liver cancer was viewed as a neoplasm that almost exclusively arose among high-risk populations in low- and middle-income countries. Incidence rates in some high-risk populations, however, have been declining, while rates in low-risk populations have been increasing, reflecting changes in underlying etiology. In this review, we highlight the evolving epidemiology of liver cancer, focusing on recent research and advances.

Recent Findings: Efforts to reduce or eliminate the risk associated with major risk factors such as hepatitis $B$ virus $(\mathrm{HBV})$, hepatitis $\mathrm{C}$ virus $(\mathrm{HCV})$ and aflatoxin $\mathrm{B}_{1}\left(\mathrm{AFB}_{1}\right)$ have met with some success. As opposed to these favorable trends, the joint epidemics of obesity and diabetes have begun to affect liver cancer rates around the world.

Summary: While there has been progress in combating the effects of some risk factors, the increasing prevalence of others poses a major threat to attempts to tackle the rising incidence of liver cancer globally.

\section{Keywords}

hepatocellular carcinoma; hepatitis B virus; hepatitis C virus; aflatoxin; Non-alcohol fatty liver disease; obesity

\section{INTRODUCTION}

Primary liver cancer is the seventh most frequently occurring cancer in the world and the fourth most common cause of cancer mortality [1]. Liver cancer incidence rates have been rising in many countries [2], and are forecast to continue increasing in the next decade [3]. The two major histologic types of primary liver cancer are hepatocellular carcinoma (HCC) and intrahepatic cholangiocarcinoma (ICC). HCC originates in hepatocytes, most commonly on a background of oxidative stress, inflammation and underlying liver disease [4], while ICC arises in cholangiocytes that line the intrahepatic bile duct. On a global scale, HCC

Correspondence to: Katherine A. McGlynn, PhD, MPH, 9609 Medical Center Drive, 6E-446, Bethesda, MD 20892, mcglynnk@mail.nih.gov.

Publisher's Disclaimer: This Author Accepted Manuscript is a PDF file of a an unedited peer-reviewed manuscript that has been accepted for publication but has not been copyedited or corrected. The official version of record that is published in the journal is kept up to date and so may therefore differ from this version.

Conflict of Interest

Jessica L. Petrick and Katherine A. McGlynn each declare no potential conflicts of interest.

Human and Animal Rights and Informed Consent

This article does not contain any studies with human or animal subjects performed by any of the authors. 
comprises approximately $75 \%$ of all liver cancers while ICC comprises approximately $12-15 \%$. As overall liver cancer rates and patterns are largely determined by HCC, this review will focus on the changing epidemiology of $\mathrm{HCC}$ in a time of transitioning risk factors, with an emphasis on recent research and advances in the past five to ten years.

\section{DEMOGRAPHIC FACTORS}

\section{Global Trends in Incidence.}

The highest incidence rates of liver cancer in the world occur in Asia and Africa (Figure 1) [5]. However, within specific geographic regions, there is great variability. For example, in Asian regions with cancer registries, between 2008 and 2012 the male age-standardized rate (ASR) per 100,000 persons ranges from 1.8 in Dindigul, India, to 69.1 in Yanting County, China [5]. While China accounts for nearly $50 \%$ of the world's burden, the country with the single highest incidence rate is Mongolia, with an estimated 2018 rate of 93.7 [1]. Outside Asia and Africa, the highest rates in the world occur in northern Central America, with Guatemala having the highest estimated rate in the region (ASR=14.9) [1]. Unfortunately, there are very few population-based cancer registries in low- and middle-income countries, which makes it difficult to examine current rates and trends over time. This lack of data makes it challenging to understand the scope of the liver cancer problem and organize intervention efforts that could be implemented.

In the interval between 1978-1982 and 2008-2012, liver cancer incidence increased in many areas of the world, notably in Oceania, North and South America, and in much of Europe (Figure 1). In contrast, incidence rates declined in many Asian countries. In the US, the 5year relative survival of liver cancer is only 18\% [6]. Prognosis is even poorer in less developed regions; thus, incidence and mortality rates are roughly equivalent in all countries.

Sex.

Gender disparity in incidence is notable around the world, with rates among males being two to three-fold higher than rates among females. High-rate areas, however, do not have greater gender disparity than do other areas. For example, the greatest disparity in incidence occurs in European countries where some registries have rates among males that are four to fivefold higher than rates among females (e.g., France male:female ratio=5.0) [5]. The gender disparity is not well understood, although most liver cancer risk factors are more prevalent in males than females. It has also been hypothesized that differences in sex steroid hormones, immune responses and epigenetics could be related to the discrepant rates [7]. In contrast to the usual gender pattern, the male:female ratio is $<1.5$ in countries ranging from Mexico in the north, through Central America, and down the Pacific coast of South America. For example, in Guatemala, the incidence rate is much more similar among males (15.8) and females (14.0) [1], though reasons for the near equivalency in rates are not known.

\section{Race and Ethnicity.}

In addition to gender differences, racial/ethnic disparities are notable in multiethnic populations. In the US, Asians/Pacific Islanders have long had the highest incidence rates of liver cancer (14.2 per 100,000), followed by American Indian/Alaskan Natives (12.6), 
Hispanics (12.1), non-Hispanic blacks (9.4), and finally, non-Hispanic whites (5.9) [6]. At the current time, HCC rates are increasing in all racial/ethnic groups except Asian/Pacific Islanders, who are now forecast to have the lowest rates of all groups in the US by 2030 $[8 \cdot \bullet]$.

In addition to racial/ethnic variability within a single location, incidence rates of individual racial/ethnic groups also vary across different geographic locations. For example, liver cancer rates among Chinese populations outside China (e.g., Chinese males in Hawaii ASR $=8.7$ per 100,000) are typically lower than the rates reported by Chinese registries (e.g., Chinese males in China ASR = 21.0) [5]. Racial/ethnic differences in rates are likely due, mainly, to variability in the prevalence of risk factors between racial/ethnic groups and between geographic locations.

\section{RISK FACTORS}

Chronic infections with hepatitis B virus (HBV) and hepatitis C virus (HCV) are estimated to be responsible for almost three-quarters (73.4\%) of HCC in the world [9], with HBV being responsible for twice as many cases as $\mathrm{HCV}[10]$.

\section{Hepatitis B Virus.}

The World Health Organization estimates that 257 million people, approximately $3.5 \%$ of world's population, are chronically infected with $\mathrm{HBV}$ and, in 2015, HBV infection was responsible for 887,000 deaths, largely due to cirrhosis and HCC [11]. Thus, among HBV carriers, the lifetime risk of dying of either cirrhosis or HCC is between $10 \%$ and $25 \%$ [12].

The future burden of HBV-related HCC, however, should decline considerably in many countries due to $\mathrm{HBV}$ vaccination to prevent infection, and efficacious therapies to treat chronic infections. As the risk of developing a chronic HBV infection is much higher if the infection is acquired early in life, the HBV vaccine has, since coming on the market in 1982, been targeted at newborns. As of 2017, 187 WHO member countries vaccinated newborns as part of their routine vaccination schedules, and global coverage with all 3 doses of HBV vaccine was estimated to be $84 \%$ [13]. Furthermore, as of 2018, 105 countries had introduced the HBV vaccine birth dose, which is critical in preventing mother-child transmission, particularly in populations where HBV carrier mothers are actively replicating virus [14]. Not all areas of the world have made equal progress with HBV vaccination, however. While most Western Pacific countries began vaccination programs in the 1990s, it is estimated that the vaccination rate in sub-Saharan Africa remains under 10\% [15].

The effectiveness of the vaccine in preventing HBV infection has been well-demonstrated in Taiwan [16]. Italy [17] and Alaska in the US [14]. In these locations, the incidence of HCC among children has also declined $[18,19]$. It is still too soon, however, for HBV vaccination to have had a significant effect on HCC rates among adults, as the first cohort of newborns to be vaccinated are only now in their thirties.

Although the HBV vaccine has no effect on established infections, treatment of chronic infections dramatically improved with the introduction in 1998 of lamivudine, the first 
nucleos $(\mathrm{t})$ ide analogue (NA). The two most commonly used first-line NAs are now entecavir and tenofovir, both introduced in the first decade of the twenty-first century. As NAs interfere with HBV replication, but do not clear the virus, they are generally prescribed for the person's lifetime. The extent to which inhibition of viral replication will reduce the risk of HCC as yet remains uncertain, although a systematic review found that several factors were associated with risk reduction, including becoming HBV surface antigen seronegative, not having cirrhosis, being younger than 50 years of age and being female [20]. Even among individuals with the greatest number of favorable factors, however, the risk of HCC remains elevated, suggesting that NA-treated persons should remain under surveillance. Recently, studies have begun to examine the effect of NA therapy over a longer period. A study from a multi-country European population reported a decreased risk of HCC after 5 years of therapy [21]. In contrast, a death certificate study in Korea reported decreased risk of liver disease mortality, but increased risk of liver cancer mortality between 1999 and 2013 [22]. As NA therapy in Korea increased dramatically during this period, the authors speculate that NA therapy may, by extending the life of persons with liver disease, increase the opportunity to develop HCC. The cumulative findings suggest that HCC risk will decline with NA therapy, and that beginning anti-viral treatment prior to the development of liver disease will have the greatest effect.

Low and middle-income countries of sub-Saharan Africa bear a substantial proportion of the global HBV burden. Many of the countries lack economic and healthcare resources to obtain access to screening, care and treatment for HBV infection [23], with fewer than $1 \%$ of HBV infections being diagnosed $[11,15]$. Some countries, however, are making progress. Since 2012, Uganda has produced a generic form of tenofovir, which is offered without charge at some treatment centers. Beginning in 2017, Senegal allowed clinics to offer tenofovir at the same low cost as HIV drugs [15]. However, HBV will likely remain a problem in subSaharan Africa for the foreseeable future.

\section{Hepatitis C Virus (HCV).}

The World Health Organization estimates that, globally, 71 million persons are chronically infected with $\mathrm{HCV}$, and 399,000 HCV-infected individuals die each year from cirrhosis or HCC [24]. HCV, unlike HBV, is rarely acquired in childhood. Following infection, 15\% to $45 \%$ of individuals will spontaneously clear the virus while the remaining persons will develop a chronic infection [24]. HCV infections are usually non-symptomatic, and chronic infections may not become clinically manifest for many years. Egypt currently has the highest rate of chronic HCV infection in the world, at 18\% [25]. In Asia, the HCV infection rate is highest in Mongolia (10\%), while rates in Europe, the US and Canada (0.5-2.5\%) are considerably lower [25].

HCV was identified in 1989, and reliable serologic tests for antibody to HCV became available in 1990. Evidence indicates that HCV existed as a low-level, endemic virus prior to the $20^{\text {th }}$ century, but spread worldwide, via a number of transmission routes, beginning around 1900 [26]. Japan was one of the first countries to experience a large-scale HCV epidemic, likely due to the use of anti-schistosomal therapy of intravenous antimony sodium tartrate beginning in the 1920s [27]. Molecular clock studies of HCV in Egypt have 
suggested a similar transmission route in that country [28]. HCV likely began circulating in the US around 1910 but became more widely disseminated between 1940 and 1960. While it has been speculated that viral spread in the US was linked to drug use among members of the 1945-1965 birth cohorts, recent evidence suggests that the spread was more likely related to nosocomial transmission [29••]. Regardless of the means of viral dissemination, the 1945-1965 US birth cohorts have a higher rate of infection than do other birth cohorts [30].

In 2010, it was estimated that the peak of the HCV-related HCC epidemic in the US would occur in 2019 with 14,000 cases per year [31]. However, recent dramatic developments in treatment of HCV may affect this estimate. Prior to 2014, HCV infection was difficult to eradicate, but with the replacement of interferon-based therapy with direct-acting antiviral (DAA) therapy, almost all HCV infections are now potentially curable [32].

In Egypt, $\mathrm{HCV}$ diagnosis, treatment, and prevention efforts have been implemented by the Egyptian Ministry of Health, with advice from the World Health Organization [33]. The Egyptian government negotiated reduced prices for sofosbuvir [33], and currently, with locally-produced generic drugs, all $\mathrm{HCV}(+)$ patients are treated with DAA therapy. Thus, Egypt's national HCV treatment program is the largest in the world [34]. In early 2018, Egypt announced a national plan to eradicate HCV by 2022 by testing the entire adult population [35].

The extent to which curing HCV infection reduces the risk of $\mathrm{HCC}$ has been the subject of a great deal of interest [36, 37]. After initial concerns that achievement of a sustained virologic response (SVR) with DAAs did not reduce the risk of HCC as much as an SVR achieved by the older interferon therapy [37], more recent analyses suggest that initial DAAinterferon comparisons did not correct for differences in the patient populations [38]. Interferon-based therapy was offered to a more highly selected group of persons, thus biasing the results toward a more favorable outcome [39]. Recent evidence suggests that the reduction in HCC risk with DAA-therapy is considerable [40]. The risk of HCC remains somewhat elevated, particularly among persons with cirrhosis, but the long-term outcome suggests that DAA-therapy will have a substantial effect on HCC rates in the future. DAAs remain expensive, but their price will likely decrease as more drugs come on the market and with widespread use the incidence of HCV-related HCC should notably decline. As yet, there is no vaccine against $\mathrm{HCV}$ infection, but standard public health measures, including testing of all donated blood, syringe and needle exchange programs for intravenous drug users, and safe handling and disposal of sharps and waste greatly reduce the risk of new $\mathrm{HCV}$ infections. In addition, if the HCV eradication in Egypt is successful, it will offer a blueprint for ambitious eradication programs around the world.

\section{Aflatoxins.}

Aflatoxins, produced by fungi of the Aspergillus species, contaminate maize, ground nuts, tree nuts, and other food staples in warm, humid environments around the world. The most potent aflatoxin, aflatoxin $\mathrm{B}_{1}\left(\mathrm{AFB}_{1}\right)$, is hepatocarcinogenic in a variety of animal species, as well as in humans [41]. A meta-analysis of studies conducted in Asia and Africa, areas where $\mathrm{AFB}_{1}$ is known to be prevalent, has estimated the population attributable risk of $\mathrm{AFB}_{1}$ for liver cancer to be $17 \%$ (14-19\%) [42]. 
$\mathrm{AFB}_{1}$ exposure can be reduced via several means, including alterations in grain harvesting and storage methods, introduction of competitive species, and chemoprevention, as well as others [43]. The most significant demonstration of $\mathrm{AFB}_{1}$ reduction, to date, has occurred in China where changing economic policies in the mid-1980's permitted the replacement of maize for rice in some high-risk FICC areas. These policies greatly diminished exposure to $\mathrm{AFB}_{1}$ among the population and are credited with being responsible for the decline in liver cancer rates in those regions $[44,45]$. $\mathrm{AFB}_{1}$ reduction alone, however, only solves part of the problem in many regions as $\mathrm{AFB}_{1}$ tends to co-occur with endemic FIBV infection. The effect of the two factors combined is particularly deleterious as they have a synergistic effect on increasing risk of HCC [42], thus the single most effective way to reduce the risk of $\mathrm{AFB}_{1}$ is to vaccinate against $\mathrm{HBV}$. In countries where $\mathrm{AFB}_{1}$ exposure does not occur with $\mathrm{HBV}$, a scenario that appears to occur in high-risk HCC countries of Central America [46], $\mathrm{AFB}_{1}$ abatement alone is more urgent. In such populations, it will be critical to determine whether other risk factors are interacting with $\mathrm{AFB}_{1}$ to have a synergistic effect on $\mathrm{HCC}$ risk.

\section{Alcohol and Smoking.}

Excessive alcohol consumption is a well-established cause of liver cancer [47, 48]. A US pooling project, however, found that light-to-moderate alcohol consumption (i.e., $<3$ drinks per day) was associated with a significantly decreased risk of HCC [49॰]. In a sensitivity analysis excluding non-drinkers, consumption of $0.5-<1$ drink per day remained associated with a significantly decreased risk of HCC compared to consumption of $>0-<0.5$ drinks per day. The study also found that this effect was modified by diabetes. Among individuals without diabetes, light-to-moderate consumption was associated with a 35\% decreased risk of HCC, but among individuals with diabetes, there was no association [49•]. Light-tomoderate alcohol consumption may be associated with a decreased risk of type II diabetes via increased insulin sensitivity [50]. Thus, as diabetes is an important risk factor for HCC, light-to-moderate alcohol consumption could decrease $\mathrm{HCC}$ risk by decreasing the risk of diabetes. Overall, global alcohol consumption between 2000 and 2016 decreased in a number of regions, including Africa, the Americas, the Eastern Mediterranean and Europe [51]. In contrast, consumption increased in the Western Pacific region and remained stable in the South-East Asian region [51]. As alcohol consumption is generally higher in highincome countries, declines in consumption are more likely to affect rates in those regions than in lower income regions.

In a review of 113 studies, the 2014 Surgeon General's report found that current cigarette smoking was associated with a $70 \%$ increased risk of liver cancer, while former cigarette smoking was associated with a $40 \%$ increased risk [52]. Though the risk associated with smoking is lower than the risk associated with major factors, such as $\mathrm{HBV}$ and $\mathrm{HCV}$, smoking is a more common exposure. The World Health Organization reported in 2018, however, that the number of smokers around the world fell by 29 million between 2000 and 2015 [53]. Unfortunately, most of the decline in smoking was seen in high-income countries, while the number of smokers in low and middle-income countries increased. Rising prevalence of smoking in low and middle-income countries is particularly of concern 
because these countries already carry a higher burden of liver cancer than do high-income countries.

\section{Obesity, diabetes, and metabolic syndrome.}

Excess adiposity can cause low-grade systemic inflammation, which is believed to contribute to metabolic dysregulation and the progression of nonalcoholic fatty liver disease (NAFLD) to non-alcoholic steatohepatitis, fibrosis, cirrhosis, and ultimately, liver cancer [54]. Overweight (body mass index, BMI $\geq 25$ and $<30 \mathrm{~kg} / \mathrm{m}^{2}$ ) and obesity (BMI $\geq 30 \mathrm{~kg} / \mathrm{m}^{2}$ ) are associated with $18 \%$ and $83 \%$ increased risks of liver cancer [55]. Recently, a US-based pooling project reported that each $5 \mathrm{~kg} / \mathrm{m}^{2}$ increase in BMI was associated with a $33 \%$ increased risk and a $5 \mathrm{~cm}$ increase in waist circumference was associated with an $8 \%$ increased risk of liver cancer [56].

While it is now well-established that excess adult adiposity increases the risk of liver cancer [57••], few studies have examined the effect of adiposity over the life course. Using information from the Copenhagen School Health Records Registry, a one-unit increase in BMI z-score at ages 7 or 13 years was found to be associated with a 20-30\% increased risk of liver cancer [58]. In Swedish conscription data of males aged 17-19 years, overweight was associated with a $60 \%$ increased risk, and obesity a 3.6-times increased risk, of HCC [59]. Similarly, a US cohort study reported that obesity at age 18 years was associated with 2-fold increased risk of HCC [60•]. These studies are the first evidence to suggest a role of childhood adiposity in liver cancer risk.

Type 2 diabetes is also a contributor to metabolic dysregulation and may lead to NAFLD and its sequelae [61]. Diabetes has been consistently shown to be associated with a 2.0-2.5-fold increased risk of HCC $[62,63,64,65]$. Metabolic syndrome has also been associated with a $60-81 \%$ increased risk of liver cancer, as estimated in recent meta-analyses [66, 67]. In a US-based study, metabolic syndrome was associated with a 2-fold increased HCC risk [68]. While the risks associated with obesity, diabetes, and metabolic syndrome are not as great as those for $\mathrm{HBV}$ or $\mathrm{HCV}$, the population attributable fractions (PAF) are higher for obesity and diabetes because these conditions are generally much more prevalent than are $\mathrm{HBV}$ and $\mathrm{HCV}$ infections. In the US, the PAF of HCC for metabolic disorders is $32 \%$, while the PAF for $\mathrm{HCV}$ and $\mathrm{HBV}$ are $21 \%$ and $4 \%$, respectively [69].

Obesity is a burgeoning problem for liver cancer prevention efforts, as the prevalence of obesity has nearly tripled since 1975 . Worldwide in 2016, 39\% of adults were classified as overweight and $13 \%$ were classified as obese [70]. In China, where gains have been made in liver cancer prevention with successful $\mathrm{AFB}_{1}$ and $\mathrm{HBV}$ infection reduction efforts, urbanization and "Westernization" has led to sedentary lifestyles and overnutrition, laying the groundwork for increasing rates of obesity [71•]. Obesity may confer particular risk on Asian populations as obesity-related complications, such as diabetes, occur among Asians at lower levels of BMI than among white populations $[72,73]$. The prevalence of NAFLD is estimated to be roughly equivalent (25\%) in Western and Asian countries [71•]. However, the prevalence of NAFLD in individuals with BMI $<25 \mathrm{~kg} / \mathrm{m}^{2}$ is estimated to be higher in Asian countries (8-19\%) than in Western countries ( 10\%) [71•]. These differences are, in part, explained by Asians having greater central adiposity than whites of similar BMIs [71•]. 
Thus, as rates of obesity [74] and diabetes [75] increase around the world, the proportion of liver cancer attributable to these factors will almost certainly increase in the future and may offset gains made through prevention of $\mathrm{HBV}, \mathrm{HCV}$, and $\mathrm{AFB}_{1}$.

Mechanisms underlying the obesity-liver cancer association are not fully understood. However, a potential mechanism relates to the gut microbiome and associated metabolites. The microbiota is the community of microorganisms, including fungi and bacteria, that reside within human tissues and biofluids. Dysbiosis observed during obesity is associated with a thinner gut mucous layer and disruption of the tight junction proteins, both of which lead to a dysfunctional intestinal barrier. There is evidence that the microbiota, through intestinal dysbiosis and bacterial translocation beyond the gut, contribute to hepatocarcinogenesis [76••]. Specifically, dysbiosis can lead to the release of cancerpromoting and senescence-promoting metabolites, such as the secondary bile acids which include deoxycholic acid (DCA). Recent studies have shown that certain microbes, such as Akkermansia muciniphila, are necessary to replenish the mucous barrier [78]. Additionally, A. muciniphila stimulates the production of bioactive lipids (e.g., endocannabinoids), which have key anti-inflammatory roles in the intestine and are involved in control of the intestinal barrier [77••]. Additionally, leakage through the intestinal barrier can lead to increased hepatic exposure to gut-derived microbiota-associated molecular patterns (MAMPs), including lipopolysaccharides and flagellin [76••]. Prospective collection of fecal samples to examine the gut microbiome has only just begun. Several studies, however, have examined serum markers of bacterial translocation, including immunoglobulin (Ig) A, IgG, and IgM against lipopolysaccharide (LPS) and flagellin, soluble CD14 (an LPS co-receptor), and the LPS-binding protein. In a multi-country study conducted in Europe, increased serum levels of antibodies to LPS and flagellin were associated with a 12-fold increased risk of liver cancer [79•]. Similarly, increased serum levels of anti-flagellin IgA and anti-LPS IgA were associated with a 2-3-fold increased risk of liver cancer in a Finnish cohort [80•]. While studies in humans are not yet as advanced as studies in animal models, the manipulation of the gut microbiome may potentially be a means of decreasing the risk of liver cancer in high-risk individuals.

\section{CONCLUSION}

Risk factors for liver cancer are currently in transition. The prevalence of chronic HBV and $\mathrm{HCV}$ infections are declining in many regions due to public health measures. HBV infection is preventable via vaccination, and among persons already infected with HBV, long-term viral suppression is achievable. While there is still no vaccine to prevent $\mathrm{HCV}$ infection, $\mathrm{HCV}$ has been removed from the blood supplies of most countries and HCV infection is largely curable with DAA therapies. While $\mathrm{AFB}_{1}$ contamination is more challenging to control, the $\mathrm{AFB}_{1}$-related decline China alone may have a significant effect on global liver rates as nearly $50 \%$ of the liver cancer cases occur in China. Of course, implementation of $\mathrm{HBV}$ vaccination programs, treatment of persons chronically infected with $\mathrm{HBV}$ and $\mathrm{HCV}$ and development of $\mathrm{AFB}_{1}$ prevention programs are not easily achieved in many countries. Unfortunately, the countries most in need of combating $\mathrm{HBV}$ and $\mathrm{AFB}_{1}$, such as countries in sub-Saharan Africa, are the countries with the least resources to devote to the problem. Overall, however, the global looming problems for liver cancer are the related worldwide 
epidemics of obesity, diabetes, and metabolic syndrome. These factors are already contributing to increasing rates of liver cancer in many lower-risk countries. In higher-rate countries like China, where rates of liver cancer have been declining due to successful efforts to combat $\mathrm{AFB}_{1}$ and $\mathrm{HBV}$, it is possible that the increasing prevalence of obesity and diabetes could offset these gains.

\section{Acknowledgments}

Funding: This work was supported by the National Institutes of Health Intramural Research Program, National Cancer Institute.

\section{REFERENCES}

Papers of particular interest, published recently, have been highlighted as:

- Of importance

•• Of major importance

1. Global Cancer Observatory [Internet], Lyon, France: International Agency for Research on Cancer; 2018 Accessed: November 22, 2018 Available from: http://gco.iarc.fr/today/.

2. Petrick JL, Braunlin M, Laversanne M, Valery PC, Bray F, McGlynn KA. International trends in liver cancer incidence, overall and by histologic subtype, 1978-2007. Int J Cancer. 2016;139(7): 1534-45. [PubMed: 27244487]

3. Valery PC, Laversanne M, Clark PJ, Petrick JL, McGlynn KA, Bray F. Projections of primary liver cancer to 2030 in 30 countries worldwide. Hepatology. 2017.

4. Ambade A, Mandrekar P. Oxidative stress and inflammation: essential partners in alcoholic liver disease. Int J Hepatol. 2012;2012:853175. [PubMed: 22500241]

5. Bray F, Colombet M, Mery L, Piñeros M, Znaor A, Zanetti R and Ferlay J, editors. Cancer incidence in five continents, volumes I to XI: IARC CANCERBase No. 11 [Internet], Available at: http:// ci5.iarc.fr. Accessed November 20, 2018.

6. Surveillance, Epidemiology, and End Results (SEER) Program (www.seer.cancer.gov) SEER*Stat Database: Incidence - SEER 18 Regs Research Data + Hurricane Katrina Impacted Louisiana Cases, Nov 2017 Sub (1973-2015) Total U.S, National Cancer Institute, DCCPS, Surveillance Research Program, Surveillance Systems Branch, based on the November 2017 submission.

7. Dorak MT, Karpuzoglu E. Gender differences in cancer susceptibility: an inadequately addressed issue. Front Genet. 2012;3:268. [PubMed: 23226157]

8 ••. Petrick JL, Kelly SP, Altekruse SF, McGlynn KA, Rosenberg PS. Future of Hepatocellular Carcinoma Incidence in the United States Forecast Through 2030. J Clin Oncol. 2016;34(15): 1787-94. [PubMed: 27044939] Study based on the SEER 18 Registry Database, 2000-12. Future rates of liver cancer were forecast through 30, utilizing an age-period-cohort model, and showed that rates of liver cancer are predicted to increase through 30.

9. Plummer M, de Martel C, Vignat J, Ferlay J, Bray F, Franceschi S. Global burden of cancers attributable to infections in 2012: a synthetic analysis. Lancet Glob Health. 2016;4(9):e609-16. [PubMed: 27470177]

10. Perz JF, Armstrong GL, Farrington LA, Hutin YJ, Bell BP. The contributions of hepatitis B virus and hepatitis $C$ virus infections to cirrhosis and primary liver cancer worldwide. J Hepatol. 2006;45(4):529-38. [PubMed: 16879891]

11. WHO. WHO Fact Sheet on Hepatitis B. 2018https://www.who.int/news-room/fact-sheets/detail/ hepatitis-b Accessed October 22, 2018.

12. Schweitzer A, Horn J, Mikolajczyk RT, Krause G, Ott JJ. Estimations of worldwide prevalence of chronic hepatitis B virus infection: a systematic review of data published between 1965 and 2013. Lancet. 2015;386(10003):1546-55. [PubMed: 26231459] 
13. Immunization Coverage [database on the lnternet]2018 Available from: https://www.who.int/newsroom/fact-sheets/detail/immunization-coverage. Accessed: October 4, 2018

14. Nelson NP, Easterbrook PJ, McMahon BJ. Epidemiology of Hepatitis B Virus Infection and Impact of Vaccination on Disease. Clin Liver Dis. 2016;20(4):607-28. [PubMed: 27742003]

15. Graber-Stiehl I The silent epidemic killing more people than HIV, malaria or TB. Nature. 2018;564(7734):24-6. [PubMed: 30518904]

16. Peng CY, Chien RN, Liaw YF. Hepatitis B virus-related decompensated liver cirrhosis: benefits of antiviral therapy. J Hepatol. 2012;57(2):442-50. [PubMed: 22504333]

17. Stroffolini T, Mele A, Tosti ME, Gallo G, Balocchini E, Ragni P et al. The impact of the hepatitis $\mathrm{B}$ mass immunisation campaign on the incidence and risk factors of acute hepatitis B in Italy. $\mathrm{J}$ Hepatol. 2000;33(6):980-5. [PubMed: 11131462]

18. Chang MH, You SL, Chen CJ, Liu G, Lai MW, Wu TC et al. Long-term Effects of Hepatitis B Immunization of Infants in Preventing Liver Cancer. Gastroenterology. 2016;151(3):472-80 e1. [PubMed: 27269245]

19. McMahon BJ, Bulkow LR, Singleton RJ, Williams J, Snowball M, Homan C et al. Elimination of hepatocellular carcinoma and acute hepatitis B in children 25 years after a hepatitis B newborn and catch-up immunization program. Hepatology. 2011;54(3):801-7. [PubMed: 21618565]

20. Kuang XJ, Jia RR, Huo RR, Yu JJ, Wang JJ, Xiang BD et al. Systematic review of risk factors of hepatocellular carcinoma after hepatitis B surface antigen seroclearance. J Viral Hepat. 2018;25(9):1026-37. [PubMed: 29624821]

21. Papatheodoridis GV, Idilman R, Dalekos GN, Buti M, Chi H, van Boemmel F et al. The risk of hepatocellular carcinoma decreases after the first 5 years of entecavir or tenofovir in Caucasians with chronic hepatitis B. Hepatology. 2017;66(5):1444-53. [PubMed: 28622419]

22. Choi J, Han S, Kim N, Lim YS. Increasing burden of liver cancer despite extensive use of antiviral agents in a hepatitis B virus-endemic population. Hepatology. 2017;66(5):1454-63. [PubMed: 28628942]

23. Lemoine M, Eholie S, Lacombe K. Reducing the neglected burden of viral hepatitis in Africa: strategies for a global approach. J Hepatol. 2015;62(2):469-76. [PubMed: 25457207]

24. WHO. WHO Fact Sheet on Hepatitis C 2018 http://www.who.int/news-room/fact-sheets/detail/ hepatitis-c.

25. Polaris Observatory HCVC. Global prevalence and genotype distribution of hepatitis C virus infection in 2015: a modelling study. Lancet Gastroenterol Hepatol. 2017;2(3):161-76. [PubMed: 28404132]

26. Markov PV, van de Laar TJ, Thomas XV, Aronson SJ, Weegink G, van den Berk GE et al. Colonial history and contemporary transmission shape the genetic diversity of hepatitis $\mathrm{C}$ virus genotype 2 in Amsterdam. J Virol. 2012;86(14):7677-87. [PubMed: 22573865]

27. Tanaka Y, Hanada K, Mizokami M, Yeo AE, Shih JW, Gojobori T et al. A comparison of the molecular clock of hepatitis $\mathrm{C}$ virus in the United States and Japan predicts that hepatocellular carcinoma incidence in the United States will increase over the next two decades. Proc Natl Acad Sci USA. 2002;99(24): 15584-9. [PubMed: 12438687]

28. Frank C, Mohamed MK, Strickland GT, Lavanchy D, Arthur RR, Magder LS et al. The role of parenteral antischistosomal therapy in the spread of hepatitis $\mathrm{C}$ virus in Egypt. Lancet. 2000;355(9207):887-91. [PubMed: 10752705]

29 ••. Joy JB, McCloskey RM, Nguyen T, Liang RH, Khudyakov Y, Olmstead A et al. The spread of hepatitis $\mathrm{C}$ virus genotype 1a in North America: a retrospective phylogenetic study. Lancet Infect Dis. 2016;16(6):698-702. [PubMed: 27039040] This is the first study to report that increased prevalence in the birth cohorts of 1945-65 in the US is likely due to nosocomial or iatrogenic transmission.

30. Yartel AK, Rein DB, Brown KA, Krauskopf K, Massoud OI, Jordan C et al. Hepatitis C virus testing for case identification in persons born during 1945-1965: Results from three randomized controlled trials. Hepatology. 2017.

31. Davis GL, Alter MJ, El-Serag H, Poynard T, Jennings LW. Aging of hepatitis C virus (HCV)infected persons in the United States: a multiple cohort model of HCV prevalence and disease progression. Gastroenterology. 2010;138(2):513-21, 21 el-6. [PubMed: 19861128] 
32. Sulkowski MS, Gardiner DF, Rodriguez-Torres M, Reddy KR, Hassanein T, Jacobson I et al. Daclatasvir plus sofosbuvir for previously treated or untreated chronic HCV infection. N Engl J Med. 2014;370(3):211-21. [PubMed: 24428467]

33. Elgharably A, Gomaa AI, Crossey MM, Norsworthy PJ, Waked I, Taylor-Robinson SD. Hepatitis C in Egypt - past, present, and future. Int J Gen Med. 2017;10:1-6. [PubMed: 28053553]

34. Elsharkawy A, El-Raziky M, El-Akel W, El-Saeed K, Eletreby R, Hassany M et al. Planning and prioritizing direct-acting antivirals treatment for $\mathrm{HCV}$ patients in countries with limited resources: Lessons from the Egyptian experience. J Hepatol. 2017.

35. Mourad M, Masri L. Millions flock to free tests as Egypt seeks to eradicate hepatitis C. Reuters. 2018 December 3. Available from: https://www.reuters.com/article/us-health-egypt-hepatitis-c/ millions-flock-to-free-tests-as-egvpt-seeks-to-eradicate-hepatitis-c-idUSKBN1O21IO?il=0.

36. Li DK, Ren Y, Fierer DS, Rutledge S, Shaikh OS, Lo Re V 3rd, et al. The short-term incidence of hepatocellular carcinoma is not increased after hepatitis $\mathrm{C}$ treatment with direct-acting antivirals: An ERCHIVES study. Hepatology. 2018;67(6):2244-53. [PubMed: 29205416]

37. Ravi S, Axley P, Jones D, Kodali S, Simpson H, McGuire BM et al. Unusually High Rates of Hepatocellular Carcinoma After Treatment With Direct-Acting Antiviral Therapy for Hepatitis C Related Cirrhosis. Gastroenterology. 2017;152(4):911-2. [PubMed: 28161225]

38. Kanwal F, Kramer J, Asch SM, Chayanupatkul M, Cao Y, El-Serag HB. Risk of Hepatocellular Cancer in HCV Patients Treated With Direct-Acting Antiviral Agents. Gastroenterology. 2017;153(4):996-1005 e1. [PubMed: 28642197]

39. Nahon P, Layese R, Bourcier V, Cagnot C, Marcellin P, Guyader D et al. Incidence of Hepatocellular Carcinoma After Direct Antiviral Therapy for HCV in Patients With Cirrhosis Included in Surveillance Programs. Gastroenterology. 2018;155(5):1436-50 e6. [PubMed: 30031138]

40. Nahon P, Bourcier V, Layese R, Audureau E, Cagnot C, Marcellin P et al. Eradication of Hepatitis C Virus Infection in Patients With Cirrhosis Reduces Risk of Liver and Non-Liver Complications. Gastroenterology. 2017;152(1):142-56 e2. [PubMed: 27641509]

41. IARC. Overall evaluations of carcinogenicity: an updating of IARC Monographs volumes 1 to 42. IARC Monogr Eval Carcinog Risks Hum, Suppl. 71987.

42. Liu Y, Chang CC, Marsh GM, Wu F. Population attributable risk of aflatoxin-related liver cancer: systematic review and meta-analysis. Eur J Cancer. 2012;48(14):2125-36. [PubMed: 22405700]

43. Kumar P, Mahato DK, Kamle M, Mohanta TK, Kang SG. Aflatoxins: A Global Concern for Food Safety, Human Health and Their Management. Front Microbiol. 2016;7:2170. [PubMed: 28144235]

44. Chen JG, Egner PA, Ng D, Jacobson LP, Munoz A, Zhu YR et al. Reduced aflatoxin exposure presages decline in liver cancer mortality in an endemic region of China. Cancer Prev Res (Phila). 2013;6(10):1038-45. [PubMed: 23963804]

45. Sun Z, Chen T, Thorgeirsson SS, Zhan Q, Chen J, Park JH et al. Dramatic reduction of liver cancer incidence in young adults: 28 year follow-up of etiological interventions in an endemic area of China. Carcinogenesis. 2013;34(8):1800-5. [PubMed: 23322152]

46. Smith JW, Kroker-Lobos MF, Lazo M, Rivera-Andrade A, Egner PA, Wedemeyer H et al. Aflatoxin and viral hepatitis exposures in Guatemala: Molecular biomarkers reveal a unique profile of risk factors in a region of high liver cancer incidence. PLoS One. 2017;12(12):e0189255. [PubMed: 29236788]

47. Bagnardi V, Rota M, Botteri E, Tramacere I, Islami F, Fedirko V et al. Alcohol consumption and site-specific cancer risk: a comprehensive dose-response meta-analysis. Br J Cancer. 2015;112(3): 580-93. [PubMed: 25422909]

48. Turati F, Galeone C, Rota M, Pelucchi C, Negri E, Bagnardi V et al. Alcohol and liver cancer: a systematic review and meta-analysis of prospective studies. Ann Oncol. 2014;25(8):1526-35. [PubMed: 24631946]

49 •. Petrick JL, Campbell PT, Koshiol J, Thistle JE, Andreotti G, Beane-Freeman LE et al. Tobacco, alcohol use and risk of hepatocellular carcinoma and intrahepatic cholangiocarcinoma: The Liver Cancer Pooling Project. Br J Cancer. 2018;118(7):1005-12. [PubMed: 29520041] Pooled 
analysis of 14 US-based cohorts. This study reported smoking cessation and light-to-moderate drinking may reduce the risk of HCC.

50. Schrieks IC, Heil AL, Hendriks HF, Mukamal KJ, Beulens JW. The effect of alcohol consumption on insulin sensitivity and glycemic status: a systematic review and meta-analysis of intervention studies. Diabetes Care. 2015;38(4):723-32. [PubMed: 25805864]

51. WHO. Global status report on alcohol and health 2018. Geneva: World Health Organization; 2018.

52. United States Surgeon General. The health consequences of smoking--50 years of progress : a report of the surgeon general. Rockville, MD: U.S. Department of Health and Human Services; 2014.

53. WHO. WHO global report on trends in prevalence of tobacco smoking 2000-2025, second edition Geneva: World Health Organization; 2018.

54. Alzahrani B, Iseli TJ, Hebbard LW. Non-viral causes of liver cancer: does obesity led inflammation play a role? Cancer Lett. 2014;345(2):223-9. [PubMed: 24007864]

55. Chen Y, Wang X, Wang J, Yan Z, Luo J. Excess body weight and the risk of primary liver cancer: an updated meta-analysis of prospective studies. Eur J Cancer. 2012;48(14):2137-45. [PubMed: 22446023]

56. Campbell PT, Newton CC, Freedman ND, Koshiol J, Alavanja MC, Beane Freeman LE et al. Body Mass Index, Waist Circumference, Diabetes, and Risk of Liver Cancer for U.S. Adults. Cancer Res. 2016;76(20):6076-83. [PubMed: 27742674]

57 •. Lauby-Secretan B, Scoccianti C, Loomis D, Grosse Y, Bianchini F, Straif K et al. Body Fatness and Cancer--Viewpoint of the IARC Working Group. N Engl J Med. 2016;375(8):794-8. [PubMed: 27557308] Comprehensive report, examining the association between obesity and cancer. This review reports that obesity increases the risk of 13 types of cancer, with strong associations shown for obesity-liver cancer.

58. Berentzen TL, Gamborg M, Holst C, Sorensen TI, Baker JL. Body mass index in childhood and adult risk of primary liver cancer. J Hepatol. 2014;60(2):325-30. [PubMed: 24076363]

59. Hagstrom H, Tynelius P, Rasmussen F. High BMI in late adolescence predicts future severe liver disease and hepatocellular carcinoma: a national, population-based cohort study in 1.2 million men. Gut. 2018;67(8): 1536-42. [PubMed: 28320770]

60 •. Yang B, Petrick JL, Kelly SP, Graubard BI, Freedman ND, McGlynn KA. Adiposity across the adult life course and incidence of primary liver cancer: The NIH-AARP cohort. Int J Cancer. 2017;141(2):271-8. [PubMed: 28411388] Prospective US cohort study examining BMI at four timepoints throughout the adult lifecourse. This study suggests that maintaining a healthy BMI throughout the lifetime may reduce liver cancer risk

61. Adams LA, Lymp JF, St Sauver J, Sanderson SO, Lindor KD, Feldstein A et al. The natural history of nonalcoholic fatty liver disease: a population-based cohort study. Gastroenterology. 2005;129(1):113-21. [PubMed: 16012941]

62. El-Serag HB, Hampel H, Javadi F. The association between diabetes and hepatocellular carcinoma: a systematic review of epidemiologic evidence. Clin Gastroenterol Hepatol. 2006;4(3):369-80. [PubMed: 16527702]

63. Chen J, Han Y, Xu C, Xiao T, Wang B. Effect of type 2 diabetes mellitus on the risk for hepatocellular carcinoma in chronic liver diseases: a meta-analysis of cohort studies. Eur J Cancer Prev. 2015;24(2):89- 99. [PubMed: 24809655]

64. Wang C, Wang X, Gong G, Ben Q, Qiu W, Chen Y et al. Increased risk of hepatocellular carcinoma in patients with diabetes mellitus: a systematic review and meta-analysis of cohort studies. Int J Cancer. 2012; 130(7): 1639-48. [PubMed: 21544812]

65. Wang P, Kang D, Cao W, Wang Y, Liu Z. Diabetes mellitus and risk of hepatocellular carcinoma: a systematic review and meta-analysis. Diabetes Metab Res Rev. 2012;28(2):109-22. [PubMed: 21898753]

66. Jinjuvadia R, Patel S, Liangpunsakul S. The association between metabolic syndrome and hepatocellular carcinoma: systemic review and meta-analysis. J Clin Gastroenterol. 2014;48(2): 172-7. [PubMed: 24402120]

67. Esposito K, Chiodini P, Colao A, Lenzi A, Giugliano D. Metabolic syndrome and risk of cancer: a systematic review and meta-analysis. Diabetes Care. 2012;35(11):2402-11. [PubMed: 23093685] 
68. Welzel TM, Zeuzem S, El-Serag HB, Davila JA, McGlynn KA. Metabolic syndrome increases the risk of primary liver cancer in the United States: a study in the SEER-Medicare database. Hepatology. 2011;54(2):463-71. [PubMed: 21538440]

69. Makarova-Rusher OV, Altekruse SF, McNeel TS, Ulahannan S, Duffy AG, Graubard BI et al. Population attributable fractions of risk factors for hepatocellular carcinoma in the United States. Cancer. 2016; 122(11): 1757-65. [PubMed: 26998818]

70. World Health Organization. Fact Sheet on Overweight and Obesity. 2018 Available at: https:// www.who.int/news-room/fact-sheets/detail/obesitv-and-overweight. Accessed November 20, 2018.

71 •. Fan JG, Kim SU, Wong VW. New trends on obesity and NAFLD in Asia. J Hepatol. 2017;67(4): 862-73. [PubMed: 28642059] Report on the most recent prevalence estimates of non-alcoholic fatty liver disease in Asian populations.

72. Yoon KH, Lee JH, Kim JW, Cho JH, Choi YH, Ko SH et al. Epidemic obesity and type 2 diabetes in Asia. Lancet. 2006;368(9548):1681-8. [PubMed: 17098087]

73. Ramachandran A, Chamukuttan S, Shetty SA, Arun N, Susairaj P. Obesity in Asia--is it different from rest of the world. Diabetes Metab Res Rev. 2012;28 Suppl 2:47-51. [PubMed: 23280866]

74. James WP. The epidemiology of obesity: the size of the problem. J Intern Med. 2008;263(4):33652. [PubMed: 18312311]

75. Shaw JE, Sicree RA, Zimmet PZ. Global estimates of the prevalence of diabetes for 2010 and 2030. Diabetes Res Clin Pract. 2010;87(1):4-14. [PubMed: 19896746]

$76 \bullet \bullet$ Yu LX, Schwabe RF. The gut microbiome and liver cancer: mechanisms and clinical translation. Nat Rev Gastroenterol Hepatol. 2017;14(9):527-39. [PubMed: 28676707] Review of the mechanistic links between the microbiome, leaky gut, and liver cancer.

77 •. Cani PD, Jordan BF. Gut microbiota-mediated inflammation in obesity: a link with gastrointestinal cancer. Nat Rev Gastroenterol Hepatol. 2018;15(11):671-82. [PubMed: 29844585] Review suggesting that leakage of microbial components across the intestinal barrier could be the mechanism underlying obesity and liver cancer risk.

78. Everard A, Belzer C, Geurts L, Ouwerkerk JP, Druart C, Bindels LB et al. Cross-talk between Akkermansia muciniphila and intestinal epithelium controls diet-induced obesity. Proc Natl Acad Sci U S A. 2013;110(22):9066-71. [PubMed: 23671105]

79 •. Fedirko V, Tran HQ, Gewirtz AT, Stepien M, Trichopoulou A, Aleksandrova K et al. Exposure to bacterial products lipopolysaccharide and flagellin and hepatocellular carcinoma: a nested casecontrol study. BMC Med. 2017;15(1):72. [PubMed: 28372583] Nested case-control study based in the European Prospective Investigation into Cancer and Nutrition (EPIC) cohort study. This was the first epidemiologic study examining markers of bacterial translocation in relation to liver cancer risk, reporting that the highest quartile of antibody response to LPS and flagellin was associated with a 12-times increased risk of liver cancer

80 • Yang BPJ, Thistle JE, Pinto L, Kemp T, Gewirtz AT, Tran HQ, Waterboer T, Fedirko V, Jenab M, Weinstein S, Albanes D, McGlynn KA. Bacterial translocation and risk of liver cancer in a prospective Finnish cohort. Cancer Epidemiol Biomarkers Prev. 2018:ln Press.Nested casecontrol study in the Alpha-Tocopherol, Beta-Carotene Cancer Prevention (ATBC) cohort. This study reported that anti-flagellin IgA and anti-LPS IgA were associated with a 2-3-times increased risk of liver cancer. 


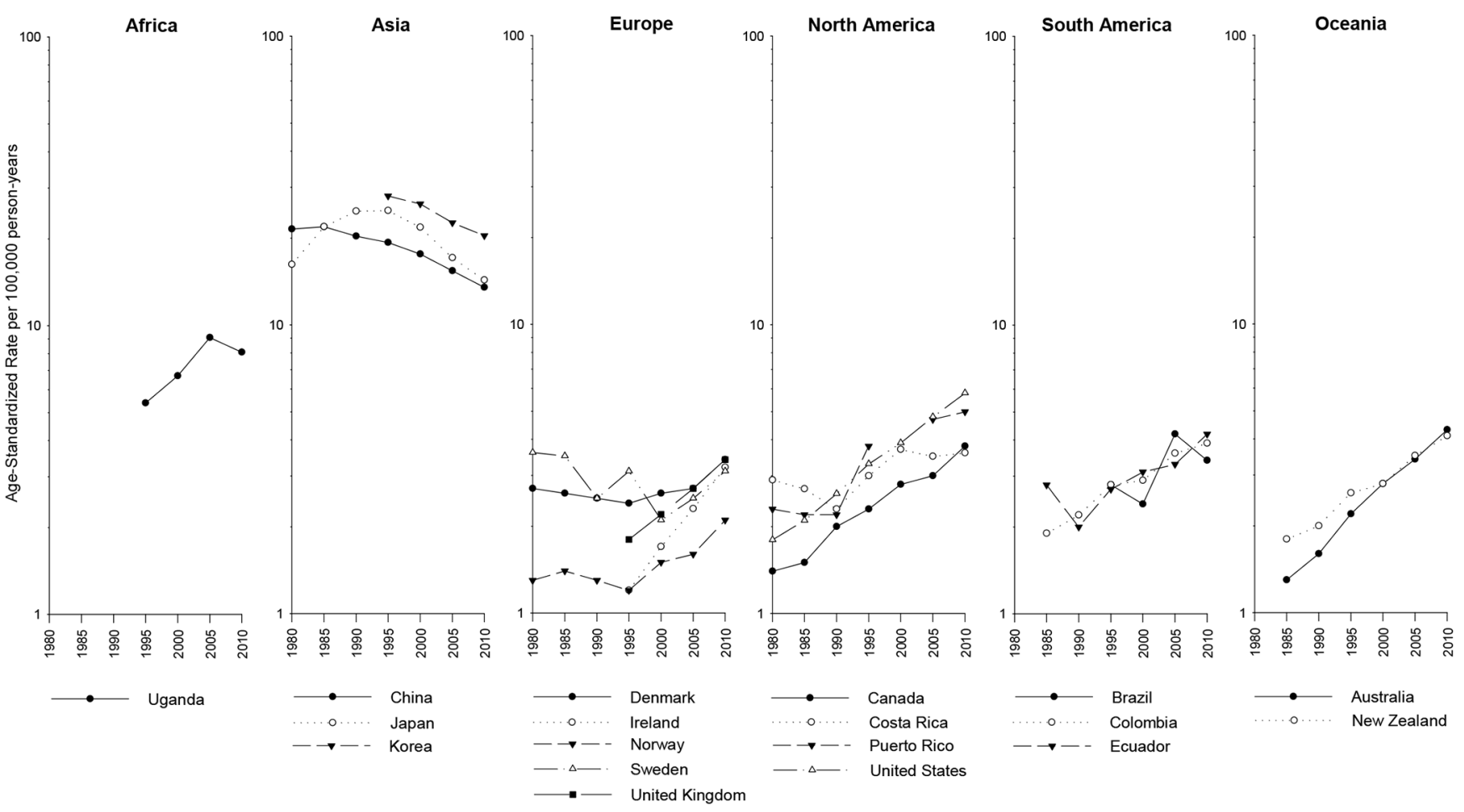

Figure 1.

Trends in liver cancer incidence rates in males and females by country, 1978-2012. (Bray F, Colombet M, Mery L, Piñeros M, Znaor A, Zanetti R and Ferlay J, editors. Cancer incidence in five continents, volumes I to XI: IARC CANCERBase No. 11 [Internet], Available at: http://ci5.iarc.fr. Accessed November 20, 2018.) 